\title{
TEORIAS POLÍTICAS TRADICIONAIS E TEORIA CRÍTICA
}

\author{
Alessandro Pinzani \\ é professor de ética e filosofia política na Universidade Federal de Santa Catarina (UFSC) e \\ livre docente em filosofia pela Universidade de Tübingen. Florianópolis, SC, Brasil. \\ E-mail:<alepinzani@gmail.com> \\ http://dx.doi.org/10.1590/0102-057091/102
}

Pois cada estudo da sociedade que seja valioso deve possuir caráter filosófico e cada filosofia valiosa deve estar preocupada com a natureza da sociedade humana.

P. WINCH ${ }^{1}$

A pesquisa social de qualquer tipo avança graças às ideias, éé somente disciplinada pelos fatos.

$$
\text { C. W. Mills }{ }^{2}
$$

A ideia de verdade científica não pode ser dissociada da [ideia] de uma sociedade verdadeira.

T. W. AdORNO ${ }^{3}$

O Congresso da Sociedade Alemã de Sociologia de 1961 entrou na história pela discussão entre Adorno e Popper

\footnotetext{
1 "For any worthwhile study of society must be philosophical in character and any worthwhile philosophy must be concerned with the nature of human society" (Winch, 1958, p. 3).

2 "Social research of any kind is advanced by ideas; it is only disciplined by facts" (Mills, 2000, p. 71).

3 Adorno (1983, p. 234).
} 
que deu início à chamada disputa sobre o positivismo, tendo como participantes mais ativos dois "alunos" dos mestres, a saber, Jürgen Habermas e Hans Albert. Tal disputa trouxe à tona um mal-estar presente em muitos cientistas sociais alemães perante a atitude positivista dominante na época (Adorno, 2014). Já passaram mais de cinquenta anos, mas ainda é possível ler ou ouvir as mesmas críticas e acusações recíprocas entre, de um lado, os que estão convencidos de que as ciências sociais devem ser wertfrei [axiologicamente neutras] e limitar-se a uma descrição objetiva baseada em fatos e, de outro, os que pensam que o modelo das ciências naturais não pode ser seguido pelas ciências sociais e que a neutralidade axiológica é uma quimera. A disputa não se limita à área da sociologia, mas se deslocou também para a da teoria política. Este artigo pretende oferecer algumas contribuições para esclarecer um ponto central nesse debate e para defender um modo específico de fazer teoria política.

Defenderei, primeiramente, a ideia de que a teoria política é intrínseca e inevitavelmente normativa, mesmo quando afirma ser meramente descritiva e empírica. Ao mesmo tempo, mostrarei que há diferenças entre teorias normativas "externalistas" e teorias normativas que assumem uma posição de crítica imanente. Em seguida defenderei uma posição próxima daquela defendida por Adorno em 1961, a saber, a necessidade de desenvolver uma teoria crítica da sociedade, que rechace a atitude positivista ou cientificista e reconheça as contradições inerentes ao seu próprio objeto. Para tanto, retomarei algumas das considerações de Adorno e lhes acrescentarei algumas observações sobre possíveis caminhos para uma Teoria Crítica que tenha como objeto a sociedade contemporânea.

\section{A inevitável normatividade das teorias políticas}

Nesta primeira seção defenderei que toda teoria política assume inevitavelmente uma posição normativa mais ou 
menos explícita, mais ou menos "forte". Para fundamentar essa tese, me servirei primeiramente de algumas considerações de Isaiah Berlin, bem como de Theodor Adorno e Jürgen Habermas, que apresentam vários pontos em comum em suas críticas à presumida neutralidade axiológica das ciências sociais. Em seguida explicarei em que consiste o mencionado recurso a posições normativas por parte da teoria política e introduzirei algumas distinções entre teoria normativa, teoria prescritiva e Teoria Crítica.

\section{As críticas de Berlin ao positivismo}

Em 1961, isto é, no mesmo ano em que se iniciou a mencionada disputa sobre o positivismo na sociologia alemã, Isaiah Berlin publicou o ensaio "La théorie politique existe-t-elle?", cuja tradução em inglês saiu no ano seguinte com o título "Does Political Theory Still Exist?" (Berlin, 1999 ${ }^{4}$. Segundo o autor, além das proposições analíticas e das sintéticas que podem ser comprovadas empiricamente (esses são os únicos dois tipos de proposições aceitos pelo então dominante positivismo lógico), há um terceiro tipo de proposições, que diz respeito a questões genuinamente filosóficas. Algumas delas concernem a conceitos como liberdade, Estado, autoridade etc., sobre cujo significado não há nenhum ou pouco consenso e que não podem ser objeto de pesquisas empíricas, pois remetem não a fatos, mas à nossa capacidade de interpretar e conceitualizar nossa vida (cf. Vincent, 2004, p. 95). Assim, para responder a perguntas sobre o que significa liberdade ou sobre quais são os limites do poder estatal, não podemos apontar para fatos empíricos ou operar uma dedução a partir de premissas dadas. Não

\footnotetext{
4 A versão francesa saiu na Revue française de science politique, v. 11, pp. 309-337, 1961. A inglesa saiu em: LASLETT, P.; RUNCIMAN, W. G. (eds). Philosophy, Politics and Society. Oxford: Blackwell, 1962. Neste texto é citada sua reedição como Berlin (1999). O artigo se situa em um contexto histórico, no qual apareceram vários textos sobre o tema (Cobban, 1953; Easton, 1951; Laslett, 1956). Contudo, não o reconstruirei aqui.
} 
há sequer consenso sobre o método para procurar uma resposta para tais questões, contrariamente ao que acontece com as questões das ciências naturais ou da matemática ${ }^{5}$. Questões desse tipo, por exemplo: “O que é a justiça?”, não podem ser respondidas apontando-se para um fato específico, mas implicam de maneira essencial a formulação de juízos de valor (Berlin, 1999, p. 146). Poder-se-ia replicar, como faziam os positivistas lógicos da época, que, por isso, tais questões são vazias e sem sentido e não deveriam sequer ser colocadas. Por outro lado, poder-se-ia replicar também que nós, os humanos, somos seres autointerpretantes, para usar uma expressão de Charles Taylor (1985), e que, portanto, nos é impossível evitar essas questões e, ao pô-las, é inevitável que abandonemos o terreno dos dados e dos fatos empiricamente observáveis para adentrarmos nas areias movediças dos juízos axiológicos e normativos.

Como salienta Berlin, perguntar "por que obedecer?" 60 não é a mesma coisa que perguntar "por que os seres humanos obedecem?" (isso pode ser respondido pela psicologia, pela antropologia ou pela sociologia servindo-se de dados recolhidos por meio de pesquisas empíricas), ou perguntar "quem obedece a quem, onde e quando, e sob quais circunstâncias?" (isso também pode ser respondido com análises empíricas, como acontece na ciência política comparativa). O que se está perguntando aqui é qual seria a justificação para obedecer (Berlin, 1999, p. 148). Estamos perguntando por razões para agir de certa forma e não de outra, e tal pergunta admite mais de uma resposta, conforme os valores que são invocados por quem a responde, conforme o sentido atribuído a conceitos como "autoridade, liberdade" etc., ou conforme o estatuto normativo atribuído a proposições como "há uma obrigação de obedecer ao soberano".

\footnotetext{
${ }^{5}$ É nesse sentido que Berlin usa termos como "quase ciências" ou "terra de ninguém" para referir-se a ciências sociais como a psicologia, a sociologia ou a semântica (Berlin, 1999, p. 145).
} 
Uma resposta única e unívoca só seria possível em uma sociedade na qual houvesse consenso unânime sobre quais são os fins a serem perseguidos pela comunidade política por meio de suas instituições, pois, nesse caso, seria possível responder apontando para essa finalidade. Assim, a resposta possuiria caráter explicativo e assumiria uma forma do tipo: "É preciso obedecer para que o fim comum X seja alcançado”. No máximo haveria discussão acerca dos melhores caminhos para chegar a tais fins, ou seja, sobre os meios. Se conseguíssemos mostrar com dados empíricos que a obediência serve para este fim, então a resposta seria uma, e apenas uma. Questões políticas seriam reduzidas assim a questões técnicas, como afirmam os defensores de um modelo tecnocrático de política, mas isso não eliminaria a necessidade de apresentar razões para escolher um meio em vez de outro - razões que nem sempre podem ser deduzidas simplesmente de premissas comumente aceitas (Berlin, 1999), como demonstram, por exemplo, as inúmeras divergências entre economistas sobre as maneiras mais adequadas para promover o crescimento econômico de um país. Em suma, também os tecnocratas se deparam com juízos acerca da validade de suas soluções, ainda que se trate de uma avaliação instrumental e não axiológica. Em geral, por mais que recusem questões relativas aos fins (por exemplo, por mais que aceitem como óbvia a finalidade do crescimento econômico), em primeiro lugar, não estão isentos de serem chamados a defender sua posição e, em segundo, estão aceitando implicitamente como válido o juízo axiológico e normativo de que o fim em questão é bom e deve ser perseguido. Essa assunção implícita do valor positivo de certa finalidade e da prescrição normativa de persegui-la é característica de muitas ciências sociais que se pretendem axiologicamente neutras e dizem recusar qualquer normatividade moral ou ética. 
Fora o caso limite e, na realidade, puramente ideal de uma sociedade na qual reinaria um consenso sobre uma finalidade comum, sempre haverá conflitos sobre as respostas a questões como as sobre justiça ou obediência mencionadas anteriormente. É impossível, afirma Berlin, alcançar neutralidade com asserções sobre o que é democracia ou liberdade:

A ideia de uma teoria ou de um modelo de ação humana (oposta, digamos, a um comportamento meramente animal) que seja completamente wertfrei se funda sobre uma concepção errada e ingênua do que devem ser objetividade e neutralidade nos estudos sociais (Berlin, 1999, p. 158).

Segundo Berlin, as tentativas de transformar a filosofia política e moral em uma ciência empírica fracassaram porque "nossas noções políticas são parte de nossa concepção do que significa ser humano, e esta não é somente uma questão de fato, assim como as ciências naturais concebem os fatos" (Berlin, 1999, p. 162). Por isso, conforme o autor, "os que se limitam a observar o comportamento humano e a formular hipóteses sobre ele (psicólogos, sociólogos, historiadores), por mais profundos e originais que sejam, não são, enquanto tais, teóricos políticos" (Berlin, 1999, p. 167). Para fazer teoria política, portanto, é necessário lançar mão de instrumentos conceituais diferentes dos das ciências empíricas ou descritivas, a saber, dos instrumentos característicos da filosofia.

A crítica de Adorno e Habermas ao positivismo

A posição de Berlin está de acordo em vários pontos com a que Adorno e Habermas defendem na mencionada 
disputa sobre o positivismo na sociologia alemã ${ }^{6}$. Eles também recusam o apelo positivista a fatos ou dados empíricos como únicos critérios de verdade ou de cientificidade e salientam a importância dos conceitos como algo distinto dos fatos empíricos e, contudo, necessários para uma correta compreensão dos fenômenos sociais. Nesse contexto, nos ocuparemos da crítica adorniana ao fato de o positivismo não conceber a sociedade como totalidade, e da crítica habermasiana à distinção rígida entre fatos e valores que caracteriza não somente a sociologia positivista, mas também a inspirada por Weber.

A sociologia positivista não tem como seu objeto a sociedade como uma totalidade, mas fenômenos sociais isolados. Ela "parte de opiniões, de modos de comportamento, da autocompreensão dos sujeitos singulares e da sociedade, em vez de partir desta” (Adorno, 1983, p. 220). Contra essa visão, Adorno defende que "os fatos não são aquilo tido por último e impenetrável pelo que os considera a sociologia dominante [...]. Neles se manifesta algo que eles mesmos não são" (Adorno, 1983, p. 222-223), pois eles apontam para uma totalidade subjacente que lhes dá sentido. Por isso, não é pensável limitar-se à mera coleção e enumeração dos fatos, mas é necessário interpretá-los. Cada interpretação, porém, transcende os fatos e os liga a conceitos como o de sociedade, por exemplo, que não são dados empiricamente ${ }^{7}$.

Essa crítica à visão positivista representa um elemento recorrente do pensamento de Adorno acerca da teoria social. Em suas preleções sobre os "Elementos filosóficos de

\footnotetext{
6 Também a crítica de Adorno aos sociólogos positivistas alemães se insere em um contexto mais amplo, no qual o positivismo dominante na sociologia (não somente na Alemanha) encontra oposição por parte de autores não considerados mainstream. Um exemplo disso se encontra no livro A imaginação sociológica, de C. Wright Mills, cujo ataque às teorias de Parsons e Lazarsfeld (autores criticados também por Adorno) se aproxima muito dos argumentos do pensador alemão (Mills, 2000).

7 "A interpretação dos fatos conduz à totalidade, sem que esta seja, ela própria, um fato” (Adorno, 1983, p. 223).
} 
uma teoria da sociedade" (1964), ele afirma que não é correto opor de maneira tão decidida filosofia e sociologia, e critica, por isso, o "dualismo estéril" que opõe, de um lado, "cego material" empírico e, de outro, "conceitos vazios" (Adorno, 2008, p. 25). A sociologia não é uma mera coleção de dados e não se limita a fatos empíricos, mas constrói uma teoria sobre tais fatos e sobre a sociedade. Ao fazer isso, ela escolhe os fatos que lhe parecem relevantes (por exemplo, o nível de desemprego ou de apatia política dos cidadãos de determinado país), e essa escolha nunca é wertfrei, mas baseia-se sempre sobre uma preocupação com aquilo que o teórico percebe como problemático na sociedade - o que pressupõe de sua parte um juízo axiológico ${ }^{8}$. Até a definição dos conceitos que pretende manusear em sua pesquisa não fica isenta de tal operação axiológica, como demonstra a dificuldade em chegar a uma definição universalmente aceita de conceitos como "pobreza”, "populismo", "democracia" ou "desenvolvimento". A própria maneira em que ele definirá seus conceitos influenciará de forma decisiva sua pesquisa e os resultados dela. Desse ponto de vista, não somente a sociologia nunca é wertrei, mas o próprio sociólogo escolhe os temas de sua pesquisa e as categorias descritivas, das quais ele pretende utilizar-se, sempre com base em uma posição que está marcada por certos valores e interesses, como no caso de Weber e de sua leitura do capitalismo em chave antimaterialista e antimarxista (Adorno, 1983, p. 259) ${ }^{9}$. Em sua crítica do empirismo na sociologia, quase

\footnotetext{
8 Mills chega a conclusões análogas: "Os valores estão envolvidos na seleção dos problemas que estudamos; os valores estão envolvidos também em algumas das concepções-chave que utilizamos na formulação desses problemas e os valores afetam, naturalmente, o caminho para sua resolução" (Mills, 2000, p. 78).

9 Referindo-se ao ensaio sobre A ética protestante e o espírito do capitalismo (Weber, 1988), Adorno afirma que seja o tema, seja a argumentação de Weber, não podem ser separadas "da intenção, de maneira alguma desprovida de valores, de sua crítica à doutrina marxista de superestrutura e infraestrutura. [...] A posição fundamental antimaterialista de Weber não motiva somente - como ele reconheceria - a
} 
contemporânea à de Adorno, Wright Mills chega a afirmar que cada forma de empirismo implica uma "escolha metafísica" relativamente ao que deve contar como fato ou ao que deve ser considerada a realidade. Como exemplo dessa escolha, menciona o psicologismo, ou seja, "a tentativa de explicar fenômenos sociais em termos de fatos e teorias sobre a constituição [make-up] dos indivíduos" (Mills, 2000, p. 67). Essa doutrina "repousa sobre uma explícita negação metafísica da realidade da estrutura social" ou reduz tal estrutura "a um conjunto de meios sociais [milieux]" (Mills, 2000, p. 67). Isso conduz à "idéia de que, se estudarmos uma série de indivíduos e seus meios sociais, os resultados de nossos estudos poderão de alguma maneira chegar a constituir um conhecimento da estrutura social” (Mills, 2000, p. 67). Mas isso significa também que cada escolha "metafísica" implica uma tomada de posição relativamente à existência ou não da sociedade como totalidade - posição que não é politicamente neutra, como afirma Adorno.

A recusa de servir-se de conceitos gerais, como o de sociedade, longe de ser expressão de uma neutralidade axiológica, representa antes uma tomada de posição em prol do status quo, uma vez que impede que seja questionada a natureza da sociedade mesma. Representa, em suma, uma defesa da "totalidade cegamente dominante" (Adorno, 1983, p. 225), cuja existência é até negada. Longe de buscar uma ciência neutra relativamente aos valores, os sociólogos positivistas defendem o valor da conservação e da aceitação do status quo como única realidade possível, sem que seja imaginável qualquer alternativa ${ }^{10}$. Nisso, diríamos hoje, eles seguem o lema característico do neoliberalismo pelo qual "there is no alternative", não há alternativa a um mundo orga-

temática de sua sociologia da religião, mas também a sua orientação, a escolha dos materiais, a trama do pensamento" (Adorno, 1983, p. 259).

10 "Todo conhecimento que voluntariamente se submete às regras desta sociedade solidificadas em ciência participa da sua falsidade" (Adorno, 1983, p. 228). 
nizado conforme os princípios neoliberais e dominado pela lógica economicista que tende a mercantilizar todo e qualquer aspecto da vida humana.

A sociologia positivista, porém, prefere desconhecer "sua interdependência com os faits sociaux, fazendo-se passar por algo absoluto e autossuficiente" (Adorno, 1983, p. 228). Contra a ideia de uma completa autonomia da ciência em relação ao seu contexto social, Adorno afirma que "a ciência, incluída a lógica formal, não é apenas força social produtiva, mas igualmente relação social de produção" e se pergunta "se isto é aceitável para os positivistas", uma vez que "abala criticamente a tese fundamental da autonomia absoluta da ciência" (Adorno, 1983, p. 217). Desse ponto de vista, a crítica de Adorno atinge um nível mais profundo do que a crítica, aparentemente análoga, de Berlin, pois não se limita a constatar a inevitabilidade de as ciências sociais recorrerem a conceitos gerais de caráter filosóficos (uma 66 posição defendida naqueles anos também por Peter Winch (1958), mas aponta para o fato de que, ao afirmarem que estariam assumindo uma posição axiologicamente neutra, os sociólogos positivistas estão, na realidade, tomando uma posição política específica, a saber, a de uma aceitação e defesa do status quo social. Em suma, longe de tratar-se de uma mera questão metodológica, tratar-se-ia de uma questão eminentemente política ${ }^{11}$.

Permanece, contudo, uma questão aberta. Weber e os teóricos que, como ele, insistem em fazer uma distinção entre esfera dos fatos e esfera dos valores, não se limitam a afirmar que o cientista social não deveria deixar-se conduzir por seus valores na elaboração de suas teorias: eles relegam os valores a um âmbito que não é passível de análise científica e de conhecimento rigoroso (o próprio cientista

11 Mills afirma que se trata de uma escolha ética, além de política (Mills, 2000). Isso pressupõe a possibilidade de distinguir os dois âmbitos - possibilidade que me parece bastante questionável. Contudo, não posso tratar do assunto neste contexto. 
escolheria defender certos valores em vez de outros com base em uma decisão irracional). Como salienta Habermas (1983a), isso produz uma série de abordagens à questão da definição da esfera dos valores que, de uma maneira ou outra, são inaceitáveis. A ética objetiva dos valores atribui a eles "um status ontológico peculiar" (não são fatos) e os considera acessíveis somente à intuição moral, negando a possibilidade da sua avaliação racional e, portanto, de uma ética cognitiva. De maneira análoga, a filosofia subjetiva dos valores "postula a existência de esferas de valores [...] num âmbito acima da história, a-histórico" (Habermas, 1983a, p. 277), e atribui a escolha entre eles à vontade dos indivíduos, abrindo as portas para uma visão decisionista, na qual os valores são já na sua formulação o resultado de decisões arbitrárias e, portanto, fundamentalmente irracionais. A estratégia adotada por Habermas para criticar a distinção rígida entre fatos e valores é a de mostrar como as ciências, inclusive as ciências naturais, não são axiologicamente neutras, nem irracionais ou decisionistas na escolha de suas posturas pré-científicas (isto é, na escolha dos valores de fundo que inspiram suas pesquisas e lhes dão sentido), mas obedecem a interesses práticos racionais que derivam de sua função social, isto é, de sua "vinculação com o sistema social de trabalho" (Habermas, 1983a, p. 284). No caso das ciências naturais, o interesse prático em questão é o domínio tecnológico da natureza para fins de conservação da existência e de reprodução social. No caso das ciências sociais contemporâneas, o interesse prático consiste na tentativa de desenvolver mecanismos de controle sobre o comportamento dos atores sociais. O saber elaborado por elas não é "puro", um saber pelo saber, mas tende a traduzir-se em técnicas de manipulação da vida social que permitam alcançar determinados fins (por exemplo, a diminuição de comportamentos considerados antissociais, ou indesejáveis, ou que podem ameaçar a coesão social) - fins que são aceitos de 
forma implícita e não são questionados. A distinção entre fatos e valores e a negação da existência dos interesses práticos das ciências são dois lados da mesma moeda.

Além disso, ao distinguir mundo dos fatos e esfera dos valores, as ciências sociais lógico-analíticas e positivas caem num paradoxo. As recomendações técnicas que deveriam resultar das proposições científicas acabam desconsiderando as condições de sua aplicação, pois elas se dão somente no contexto de uma sociedade que é imbuída de valores. Como afirma Habermas (1983a, p. 287):

As condições que definem as situações práticas nada mais são do que momentos de uma totalidade impossíveis de uma bifurcação entre uma parte viva e uma morta, fatos ou valores, meios despidos de carga valorativa e fins axiologicamente definidos. Tal divisão implicaria o malogro das condições de ação.

Sem contar que os problemas práticos, para os quais as ciências sociais pretendem fornecer soluções, "não podem ser integralmente abrangidos por uma escolha racional de meios neutros no plano valorativo" (Habermas, 1983a, p. 287). O conhecimento científico, em suma, se fundamenta sobre posturas pré-científicas, por mais que tente negá-lo ou desconsiderá-lo. Se não quer ser acusado de um irracionalismo de fundo, isto é, de escolher arbitrariamente seus valores (nos moldes do decisionismo axiológico anteriormente mencionado), deve aceitar que os valores podem ser objeto de uma análise racional e de conhecimento, ainda que não necessariamente nos moldes das ciências analítico-formais. Não somente, portanto, os cientistas sociais assumem inevitavelmente certa posição axiológica e política; além disso, devem reconhecer a possibilidade de uma análise racional de tal posição, se não querem basear sua pesquisa sobre fundamentos movediços. Faz mister, portanto, 
uma autorreflexão das ciências sobre seus interesses, a fim de ter maior clareza sobre suas escolhas metodológicas e de conteúdo, evitando, por um lado, reificar os valores implicitamente adotados pelos cientistas e, por outro, hipostasiar as forças sociais que as levam a privilegiar certos objetos e métodos em detrimento de outros (Habermas, 1983b).

A inevitabilidade do recurso a critérios axiológicos e normativos na teoria política

As críticas de Berlin, Adorno e Habermas aos sociólogos positivistas se aplicam também ao filósofo ou ao teórico da política. A escolha das temáticas e a definição dos conceitos pelos quais essas temáticas serão abordadas nunca é normativamente neutra, mas é expressão de determinados valores que levam o autor a recortar certo assunto e a decidir-se por uma abordagem específica. Todas as obras clássicas do pensamento político representam uma tentativa de refletir sobre os fenômenos que os vários autores consideram mais relevantes não de um ponto de vista meramente descritivo, mas axiológico e normativo. Quando Maquiavel escreve $O$ príncipe ou os Comentários, não quer simplesmente descrever as características dos signori e dos príncipes renascentistas, nem comentar o texto de Lívio, mas apresentar uma teoria normativa sobre quais características deveria apresentar um tipo específico de príncipe (a saber, o príncipe capaz de criar um principado novo) ou sobre as soluções que uma república deveria tomar para resolver os problemas que inevitavelmente irá enfrentar em sua história. O fato de que ele faz isso em um contexto histórico específico, usando uma terminologia que remete a tal contexto e às leituras de outros autores e, sobretudo, tendo em mente problemas peculiares (como a unificação da Itália ou a sobrevivência da pequena república florentina no contexto das lutas entre as grandes monarquias estrangeiras), 
não muda em nada a natureza normativa de suas teorias, mas a traz à tona com maior clareza.

Também os pais fundadores da sociologia se envolvem inevitavelmente em considerações de caráter normativo. Isso fica evidente no caso de Comte, que, apesar de atacar frontalmente a metafísica, acaba elaborando um pensamento que se aproxima mais de uma filosofia da história normativa (com a teoria dos três estados e com os dois princípios da ordem e do progresso) do que de uma ciência da sociedade nos moldes das ciências naturais (Comte, 1983). A noção de anomia, tão central em Durkheim (1982), é implicitamente axiológica e normativa, pois apresenta de forma negativa tal fenômeno e o considera um problema a ser resolvido. Até o conceito de "desencantamento do mundo" de Weber (1988, p. 240) está em parte ligado a uma problematização da modernidade, assim como os tipos ideais dos "especialistas sem espírito" (Fachmenschen ohne Geist) e dos "sensualistas sem coração" (Genussmenschen ohne Herz) não parecem ser figuras meramente descritivas e implicam antes uma avaliação normativa negativa. Não há, quase, conceito utilizado pelas ciências sociais e políticas que não apresente um momento implícita ou explicitamente axiológico ou normativo quando incluído no contexto de uma teoria ou de uma explicação de fenômenos sociais.

A inevitabilidade de recorrer a conceitos axiológicos e normativos não significa que a teoria política possa desinteressar-se dos fatos empíricos ou dos dados reunidos pelas ciências sociais. Como vimos, Adorno tinha alertado para o risco de opor esterilmente dados cegos e conceitos vazios. Mas a filosofia política quase nunca fez isso, ou pelo menos não o fizeram seus maiores autores. A caricatura do filósofo-herói que pretende impor à sociedade um modelo ideal construído na sua mente a partir de princípios morais abstratos - figura imaginada por Michael Walzer (1981) - é, justamente, uma caricatura, pois nenhum filósofo clássico 
fez isso, sequer o Platão d'A República (Platão 2008), que, habitualmente, é considerado o pai fundador desta maneira de se fazer teoria política, a qual é chamada, por essa razão, de platonismo político. Na realidade, o modelo de cidade descrito por Platão representa antes uma proposta de tornar mais racional a estrutura da polis grega do que uma tentativa de propor um modelo ideal no sentido de sua metafísica, isto é, um modelo correspondente a ideias de bem e de justiça imutáveis e universais - e, de fato, o próprio Platão elabora um modelo bem diferente de cidade em sua obra tardia As Leis (Platão, 1999).

Em geral, todo filósofo político parte da realidade social de seu tempo e apresenta uma proposta ou para torná-la mais racional (veremos em que sentido), ou para torná-la mais justa, ou para justificar o status quo de maneira a mostrar a racionalidade implícita nele (como no caso de Hobbes e, parcialmente, de Hegel). Ele sempre parte de um diagnóstico da maneira em que as instituições sociais, econômicas e políticas de sua sociedade funcionam realmente. Nesse sentido, a célebre afirmação de Maquiavel (2007, p. 151) segundo a qual "muitos imaginaram repúblicas e principados que nunca foram vistos" não se aplica aos grandes pensadores políticos antigos e modernos. O problema é que a filosofia clássica, pelo menos até Hegel, deixa no leitor a impressão de estar referindo-se a verdades eternas. De fato, lendo os Princípios metafísicos da doutrina do direito, de Kant (2013), é difícil não cair nessa impressão, uma vez que o título mesmo da obra se refere a uma dimensão metafísica, ou seja, subtraída à experiência empírica. Contudo, a realidade social descrita por Kant é a da Alemanha do seu tempo, e a impressão é de que, como muitos outros autores antes dele, ele também procura encontrar o que há de racional nas instituições típicas do Estado moderno e não em instituições presumidamente atemporais. Mas é com Hegel que a ideia de uma razão eterna e imutável entra definitivamente 
em crise em prol de um conceito de racionalidade histórica, que se revela por meio de instituições que são expressão do espírito de um povo em determinado momento histórico, não de uma razão universal. A filosofia política assume, assim, abertamente seu caráter de pensamento ligado a uma época específica e se libera de vez das acusações mais ou menos merecidas de "platonismo". O filósofo se preocupa em entender e explicar o desenvolvimento interno das instituições sociais e políticas, buscando superar as contingências do existente não em nome de um ideal normativo superior, mas de um olhar que permita reconhecer a racionalidade presente em tais instituições (isto é, as razões pelas quais elas são assim e o são justificadamente) e, portanto, criticá-las quando ficam aquém de sua própria racionalidade interna. A célebre afirmação hegeliana "o que é racional, isto é efetivo, e o que é efetivo, isto é racional” (Hegel, 2010, p. 41) não deve ser interpretada como uma tentativa de declarar racional o existente, pois aponta antes para a racionalidade que está presente na efetividade/realidade (o termo alemão Wirklichkeit indica ambos os conceitos) e que o filósofo deve reconhecer e mostrar aos outros. Assim, quando Hegel apresenta como racional a família nuclear burguesa do século XIX ou o moderno Estado de Direito saído da Revolução Francesa, não pretende certamente afirmar que estes são os únicos modelos de família ou de Estado possíveis, ou que são os mais racionais no sentido de uma razão universal e abstrata, mas apenas que eles representam os modelos que refletem de forma mais adequada o espírito da modernidade, no qual o indivíduo, com seus sentimentos e anseios de liberdade, já não aceita o corpete rígido da família tradicional ou das monarquias absolutistas do Antigo Regime.

O caráter axiológico e normativo da filosofia política assume, com Hegel e seus seguidores (entre os quais se encontra Marx), outra conotação. Longe de apelar para verdades últimas e universais, remete a verdades históricas 
e peculiares de certo tipo de sociedade, de certo povo ou de certa época. Por isso, o debate sobre se e até que ponto a teoria do Marx tardio seria normativa ou meramente descritiva é um falso debate. Como indicado pelo subtítulo d'O Capital, a saber, "Crítica da economia política", trata-se de uma obra que pretende explicar o funcionamento da sociedade capitalista e, ao mesmo tempo, criticar as contradições internas de tal sociedade. Em suma, qualquer que seja a posição que as teorias políticas assumem em relação à realidade social à qual se referem, elas não podem não ter consequências políticas diretas. Como observa Mills (2000, p. 80):

Ao justificar o arranjo de poder e a supremacia dos poderosos, imagens e ideias [produzidas pelos cientistas sociais] transformam poder em autoridade.

Ao criticar ou desmascarar os arranjos e os governantes dominantes elas os privam de autoridade.

Ao distrair a atenção das questões de poder e autoridade, elas distraem a atenção das realidades estruturais da própria sociedade.

Entre as três alternativas, somente a segunda merece ser considerada como atitude crítica, enquanto as outras defendem o status quo ou justificando-o diretamente ou negando a necessidade de qualquer forma de legitimação e/ou justificação das relações de poder realmente existentes.

Uma teoria política que não reflita sobre o conceito ou para me servir de um termo utilizado por Adorno - a "essência" da sociedade corre o risco de resultar em um saber vazio acerca de objetos fantasmáticos. Nenhum dos grandes pensadores políticos - de Platão a João de Salisbury, de Maquiavel a Hobbes, de Locke a Rousseau, de Kant a Hegel, de Marx a Mill, de Schmitt a Arendt, de Rawls a Habermas - deixou de refletir sobre a essência da sociedade, sobre o 
que significa para os indivíduos viver sob a ordem social, finalmente sobre o fim da própria sociedade. Ao fazerem isso, inevitavelmente eles assumiram uma perspectiva normativa e, frequentemente, prescritiva. Cabe, agora, analisar a diferença entre essas duas perspectivas.

\section{Teorias normativas e teorias prescritivas}

Ao apontar para o caráter normativo de uma teoria, não se está afirmando nada sobre seu caráter prescritivo. É certamente possível realizar uma avaliação axiológica sem prescrever explicitamente uma solução para o déficit normativo constatado pelo teórico social e político. Contudo, é evidente que há, pelo menos, uma prescrição implícita relativa à necessidade de procurar soluções para os problemas diagnosticados. A recusa de indicar soluções específicas é mais um sinal de modéstia teórica do que de uma renúncia a toda e qualquer perspectiva prescritiva.

74 Existem teorias políticas abertamente prescritivas, que tentam oferecer soluções concretas para os problemas por elas diagnosticados, mas uma teoria normativa não precisa fazer isso. Ela pode limitar-se a diagnosticar as contradições internas de um sistema econômico, por exemplo, ou a tornar explícitos os pressupostos normativos implícitos de um sistema político como a democracia liberal - que é o que Rawls pretende fazer em Liberalismo político - (cf. Rawls, 2011); ou a criticar aquelas que considera ser descrições ideológicas da sociedade, ou a mostrar as tensões internas e as contradições entre valores e ideais de uma sociedade e sua realização parcial ou nula. Ao afirmar que toda teoria política é intrínseca e inevitavelmente normativa, não estou asseverando que ela possui necessariamente caráter prescritivo. Em particular, a Teoria Crítica em sua versão adorniana se caracteriza pelo fato de não recorrer a nenhum princípio normativo positivo em sua crítica à sociedade. Cabe mencionar, nesse sentido, a crítica que o próprio Adorno faz à noção de fundamento, 
à qual opõe a ideia de justificação (Adorno, 2009, p. 7). Nas palavras de um intérprete adorniano,

a principal diferença entre fundamentação e justificação consiste em que, na primeira, começa-se pela escolha de um critério independente que servirá de padrão para avaliar o objeto, ao passo que, na segunda, inicia-se com a análise do próprio objeto, sem qualquer critério previamente estabelecido (Fleck, 2015, p. 145).

Na realidade, no caso de Adorno, há pelo menos um critério negativo que permite criticar a sociedade, a saber, o fato de ela produzir um sofrimento social evitável (sobre esse ponto, retomarei mais adiante). Mas, ainda assim, as críticas de Adorno nunca resultam na formulação positiva de soluções aos problemas sociais por ele diagnosticados.

Frequentemente, a tendência a apontar para possíveis soluções ou a deixar inexplorado esse ponto depende das diferentes concepções do que seria a política que estão embutidas não somente nas próprias teorias políticas e sociais. Às vezes prevalece nas teorias prescritivas uma visão que tende a reduzir a atividade política a uma mera ação de administração: constrói-se um aparelho estatal ou instituições sociais que correspondam a determinados princípios morais - por exemplo, aos princípios de justiça do Rawls (2002) de Uma teoria da justiça -, e todo o resto deveria seguir quase automaticamente da aplicação deles. A política se torna, assim, a arte de aplicar à realidade os corretos princípios morais - como na célebre definição kantiana dela como "teoria do direito aplicada" (Kant, 2002, p. 151) -, e a sua finalidade seria a de garantir a estabilidade e a paz social, eliminando os conflitos. Nessa visão, a teoria política acaba se transformando quase sempre em filosofia do direito, já que o direito e as leis representam o instrumento principal para a mencionada realização prática dos princípios 
morais (como no caso dos princípios de justiça rawlsianos que devem servir de orientação para a redação primeiramente da constituição de um país, secundariamente de suas leis e, finalmente, das sentenças de seus tribunais). A busca de um consenso que resolva os conflitos entre diferentes teorias abrangentes do bem, entre diferentes cosmovisões, entre diferentes sistemas de valores éticos e morais acaba assim esvaziando o caráter conflituoso e aberto da política, tirando dela sua imprevisibilidade e sua dimensão simbólica e imaginativa, que são salientadas, pelo contrário, por outras teorias, que colocam em seu centro justamente o conflito (Laclau; Mouffe, 2001), a imaginação (Ankersmit, 1996; Arendt, 2007; Geuss, 2010) ou a noção de poder (Foucault, 1979; Lukes, 2005). As teorias prescritivas tendem, em suma, a conceber a atividade política como consistindo na mera aplicação de princípios normativos pré-definidos, enquanto as teorias não prescritivas defendem que a política consiste justamente na busca pública de soluções de problemas concretos - busca que pode ser conflituosa e que pode fracassar justamente pela impossibilidade de dispor de critérios normativos universalmente aceitos.

Algo diferente acontece quando uma teoria afirma ser necessário ou desejável renunciar à dimensão axiológica e normativa em prol de uma perspectiva meramente descritiva com vistas à simples compreensão dos mecanismos sociais e políticos, sem a pretensão de julgá-los. Nesse caso, a teoria pode até reconhecer o caráter conflituoso da política e ver nela uma atividade marcada pela imprevisibilidade e pela dimensão simbólica, mas, ao fazer isso, se coloca em uma posição duplamente paradoxal. Ela pode, por um lado, negar que seja possível para o teórico julgar e avaliar os conteúdos da política, atribuindo essa capacidade somente aos agentes políticos concretos. A tarefa do teórico se limitaria assim a descrever fatos políticos, mas não fica claro por que ele estaria fazendo isso, se não com a intenção de contribuir 
para a própria atividade política, facilitando aos atores políticos a compreensão de sua própria ação, ou oferecendo-lhes um repertório para suas discussões, ou até ajudando-os a ter maior clareza sobre o que querem realizar com sua atividade política. Nesse caso, porém, ele deixa de ser um simples observador imparcial e se torna, por sua vez, ator político, tomando a posição de um participante na atividade política, de modo que sua teoria presumidamente neutra produz efeitos na práxis que a tornam automaticamente parcial. Por outro lado, ele pode reconhecer que sua teoria realiza uma avaliação axiológica e até normativa dos fenômenos sociais e políticos e, ao mesmo tempo, afirmar que ele tira seus critérios avaliativos da sociedade: é ela que define o que deve ser considerado problemático ou, pelo contrário, o que merece ser perseguido como um fim positivo. O teórico se limitaria a fornecer à sociedade os instrumentos para melhor alcançar seus fins, sejam eles quais forem (combater a anomia ou a desigualdade, ou a criminalidade, fomentar o crescimento econômico, estimular a participação ativa dos cidadãos etc.). O problema é que não é fácil identificar os fins que a sociedade considera merecedores de realização ou os critérios axiológicos e normativos que ela pretende seguir. A sociedade não é tão homogênea, e, na realidade, os fins e critérios em questão são formulados por uma parcela dela e, portanto, são parciais e expressão de uma escolha, no fundo, arbitrária, mesmo quando a parcela é majoritária (cf. Becker, 1967). Nesse sentido, o teórico compartilha essa escolha e a faz sua, tomando assim uma posição normativa.

Ao contrário do que acontece com as teorias que se recusam a reconhecer sua normatividade implícita, uma teoria política assumidamente normativa possui a vantagem de poder tematizar abertamente sua posição em relação a determinados valores e fins políticos. Ela não pretende ser imparcial, mas declara sua parcialidade e, ao fazer isso, relativiza sua posição, mostrando assim que cada teoria política é 
como em duplo sentido: é teoria sobre a política e participa concretamente da esfera política que é o seu objeto. Como afirmado já por Peter Winch (1958) e os próprios Adorno e Habermas, o teórico da política é parte da práxis que tenta conceitualizar e, por isso, sempre é obrigado a assumir uma posição política axiológica e normativa. Teoria e práxis coincidem inevitavelmente, por mais que isso possa acontecer a contragosto dos que se professam política e ideologicamente imparciais. Isso nos leva à segunda parte do artigo, na qual discutirei uma possível opção para desenvolver uma teoria social que assuma explicitamente seu engajamento em prol de valores como emancipação e eliminação do sofrimento socialmente evitável.

\section{Uma Teoria Crítica para o século XXI?}

Para apresentar a mencionada teoria social criticamente engajada, recorrerei primeiramente à distinção entre teoria tradicional e teoria crítica feita por Horkheimer em seu clássico artigo de 1937, para, em seguida, partindo de algumas considerações de Adorno, oferecer algumas considerações complementares relativas à possibilidade de desenvolver uma Teoria Crítica para o século XXI.

\section{O "comportamento crítico" de Horkheimer}

O mal-estar que o positivismo dominante nas ciências sociais suscitou no final da década de 1950 e no início da década de 1960 em autores tão diferentes como Berlin, Mills e Adorno ecoa a atitude cética de Max Horkheimer em relação à maneira tradicional de elaborar teorias científicas em geral. Esse ceticismo manifesta-se principalmente em um artigo de 1937, que é considerado como uma espécie de manifesto da Teoria Crítica da Escola de Frankfurt, intitulado "Teoria tradicional e teoria crítica" (Horkheimer, 1983). Partindo de uma definição muito genérica de teoria como "uma sinopse de proposições de um campo 
especializado, ligadas de tal modo entre si que se poderiam deduzir de algumas dessas [proposições] todas as demais" (Horkheimer, 1983, p. 125), o autor passa a criticar a tendência das teorias sociais a seguir o modelo das ciências naturais, não obstante seu objeto difira radicalmente do objeto dessas, uma vez que não somente a sociedade e os fatos sociais não são dados por natureza e são antes produtos da ação dos seres humanos ${ }^{12}$, mas até os sentidos pelos quais os percebemos são "enformados pela atividade humana" (Horkheimer, 1983, p. 133), a ponto de que já não é possível "distinguir entre o que pertence à natureza inconsciente e o que pertence à práxis social” (Horkheimer, 1983, p. 134). Nessa naturalização da produção social da realidade consiste a parcialidade das ciências sociais, que Horkheimer pretende eliminar, sem por isso renunciar completamente aos métodos de pesquisa tradicionais (Horkheimer, 1983, p. 137).

À atitude naturalizante da teoria tradicional, Horkheimer opõe um "comportamento" que ele chama de crítico (a teoria crítica é o resultado da assunção desse comportamento, portanto, e não da assunção de um método radicalmente diferente do da teoria tradicional). Consiste em considerar suspeitas "as categorias: melhor, útil, conveniente, produtivo, valioso, tais como são aceitas nesta ordem [social]" (Horkheimer, 1983, p. 138) e em recusar-se a usá-las como premissas extracientíficas de sua ação teórica. Destarte, "a separação entre indivíduo e sociedade em virtude da qual os indivíduos aceitam como naturais as barreiras que são impostas à sua atividade é eliminada na teoria crítica" (Horkheimer, 1983, p. 138). Ao fazer isso, a teoria crítica almeja a transformação da sociedade, pois, longe de considerá-la como o produto de forças naturais

12 "Os fatos concretos que estão dados na percepção devem despojar-se do caráter de mera faticidade na medida em que forem compreendidos como produtos que, como tais, deveriam estar sob o controle humano" (Horkheimer, 1983, p. 139-140). 
opacas e irracionais, pretende tornar transparentes seus mecanismos internos e "devolver" aos indivíduos a possibilidade de organizar racionalmente a ordem social. Isso Horkheimer indica com o termo de "emancipação" (Horkheimer, 1983, p. 139). Portanto, enquanto a teoria tradicional persegue um interesse pragmático em sua tentativa de ordenar e classificar dados tidos como naturais e imutáveis, a teoria crítica possui um interesse emancipatório na transformação da realidade social.

Desse ponto de vista, podemos dizer que o verdadeiro determinismo materialista não se encontra na posição de um (na época ainda) marxista como Horkheimer, mas na dos teóricos sociais que naturalizam os resultados da ação humana e concebem a sociedade como sendo movida por forças irracionais incontroláveis pelos humanos, como as chamadas "leis do mercado". Os teóricos liberais e neoliberais que assumem essa posição acabam negando valor à noção de liberdade e de autonomia individual, uma vez que - na visão naturalizante por eles defendida - o indivíduo não tem nenhuma possibilidade de controlar as forças que determinam sua vida e não pode sequer pensar em alterá-las ou aboli-las, pois "não há alternativa” possível às leis do mercado. O liberalismo econômico se fundamenta sobre uma dicotomia não eliminável, a saber, entre o indivíduo presumidamente autônomo e as leis econômicas que se lhe impõem com a mesma inexorabilidade das leis naturais. Mas como não podemos afirmar nossa liberdade perante a força da gravidade, não faz sentido falar em liberdade perante as forças do mercado, a não ser que tais forças possam ser modificadas pela livre ação dos indivíduos. Essa possibilidade, negada pelos economistas liberais e pelos teóricos neoliberais, é precisamente o objeto do interesse prático da Teoria Crítica. Nela consiste a emancipação dos indivíduos e sua apropriação da ordem social de maneira a impor-lhe a marca de sua atividade consciente e racional. 
Paradoxalmente, o liberalismo acaba negando a liberdade individual e a reduz à liberdade que tem um animal preso em uma jaula de ir incessantemente de um lado ao outro sem conseguir sair, como a pantera do homônimo poema de Rilke ${ }^{13}$. Já a Teoria Crítica afirma que na situação atual da sociedade não há liberdade nenhuma e que ela poderá ser alcançada somente quando os indivíduos tiverem o poder de controlar realmente a constituição e o funcionamento da sociedade. A Teoria Crítica se deixa conduzir pela "ideia de uma sociedade futura como coletividade de homens livres, tal como seria possível em virtude dos meios técnicos existentes" (Horkheimer, 1983, p. 145).

Esse último ponto remete àquela que será a crítica principal de Adorno à sociedade contemporânea: o fato de ela possuir os meios técnicos para eliminar o sofrimento desnecessário ligado à insatisfação de carências básicas (nutrição, saúde, prevenção sanitária etc.) e não fazer nada em relação a isso em nome do lucro de poucos ${ }^{14}$. Como tinha observado Horkheimer:

O emprego de todos os meios físicos e intelectuais de domínio da natureza é impedido pelo fato de esses

\footnotetext{
13 "De tanto olhar as grades seu olhar/ esmoreceu e nada mais aferra./ Como se houvesse só grades na terra:/ grades, apenas grades para olhar.// A onda andante e flexível do seu vulto/ em círculos concêntricos decresce,/ dança de força em torno a um ponto oculto/ no qual um grande impulso se arrefece.// De vez em quando o fecho da pupila/ se abre em silêncio. Uma imagem, então,/ na tensa paz dos músculos se instila/ para morrer no coração" (Tradução de Augusto de Campos).

14 Cabe salientar que, para Adorno, a exigência de ajudar seus membros a satisfazer suas carências pode ser colocada somente a uma sociedade que, de fato, disponha dos meios necessários: "Não seria possível, por exemplo, decretar abstratamente que todos os homens precisariam ter o que comer, enquanto as forças produtivas não fossem suficientes para a satisfação das necessidades primitivas de todos. Contudo, quando, numa sociedade em que a fome seria evitável, aqui e agora, em face da abundancia de bens existentes e evidentemente possíveis, ainda assim existe a fome, então isso exige a abolição da fome pela intervenção nas relações de produção" (Adorno, 1983, p. 260).
} 
meios, nas relações dominantes, estarem subordinados a interesses particulares e conflitivos. A produção não está dirigida à vida da coletividade nem satisfaz às exigências dos indivíduos, mas está orientada à exigência de poder de indivíduos e se encarrega também da penúria na vida da coletividade (Horkheimer, 1983, p. 142).

Segundo Adorno, o fim último da sociedade é "a conservação e satisfação da humanidade” (Adorno, 1983, p. 234), ainda que, como observa Habermas (1983b, p. 299), “a sociedade não se esgota num mero sistema destinado à autoconservação”. Sem esse fim, o próprio conceito de sociedade seria "desprovido de sentido" (Adorno, 1983, p. 234). Por isso, uma sociedade que possui os instrumentos para realizar esse fim e não o faz em nome do interesse de poucos, não pode ser considerada uma sociedade racional. Tarefa de uma teoria crítica da sociedade seria, portanto, chamar a atenção para esta contradição presente na organização social existente. Tais contradições não são internas à teoria, mas ao seu objeto, ou seja, à própria sociedade ${ }^{15}$. Por isso, Adorno afirma que a Teoria Crítica é uma teoria dialética, que parte da constatação de que há uma contradição inerente ao seu objeto e que pretende criticar tal contradição de forma imanente. Na última seção do artigo apresentarei algumas breves considerações sobre o que seria uma crítica imanente.

\footnotetext{
15 "Se nas sentenças das ciências sociais aparecem contradições lógicas, tais como aquela não irrelevante, de que o mesmo sistema social libera e escraviza as forças produtivas, então a análise teórica se capacita de remeter tais dissonâncias lógicas a momentos estruturais da sociedade, não precisando eliminá-las como simples impertinências do pensamento científico, já que somente podem ser suprimidas mediante transformação da verdade" (Adorno, 1983, p. 232). E ainda: "A contradição dialética exprime os antagonismos reais que não ficam visíveis no interior do sistema lógico-cientificista do pensamento" (Adorno, 1983, p. 233).
} 


\section{Uma crítica imanente negativa}

Como vimos, para Adorno existe pelo menos um critério normativo para criticar a sociedade contemporânea, a saber, o fato de ela provocar um sofrimento evitável no momento em que não se serve de suas potencialidades tecnológicas para satisfazer as carências básicas dos indivíduos. Já que se trata de um critério negativo que Adorno extrai de seu diagnóstico da sociedade capitalista contemporânea, e não de um princípio positivo construído através de uma argumentação racional, podemos dizer que o procedimento pelo qual o pensador alemão critica a sociedade "não é fundamentado, mas justificado" (Adorno, 2009, p. 7) ${ }^{16}$. Da mesma maneira, sua crítica é imanente no sentido de não recorrer a critérios normativos externos à sociedade em questão.

O conceito de crítica imanente é um dos mais controversos da tradição da Teoria Crítica e não surpreende que tenha sido objeto de muita discussão, inclusive em tempos recentes (cf. Stahl, 2013; Romero, 2014). Frequentemente ele é aproximado do conceito de crítica da ideologia (Pinzani, 2012), mas, neste contexto, preferirei tratá-lo separadamente e recorrer antes à distinção realizada por Moishe Postone (2014, p. 110-111; cf. Fleck, 2015, p. 149-150) entre crítica imanente positiva e negativa. A primeira se limita a constatar a discrepância entre os ideais de uma sociedade e sua realidade (nisso, ela poderia eventualmente ser considerada como uma crítica da ideologia). Ora, tal crítica pode ser feita também tendo em vista um melhoramento da realidade e sua maior adequação com os ideais. Assim, por exemplo, um crítico neoliberal poderia acusar determinada sociedade por não ser suficientemente comprometida com os ideais da meritocracia e do livre mercado e exigir que

\footnotetext{
${ }^{16}$ Em relação à relevância de tal critério negativo, ver Adorno (1996, p. 261), em que o filósofo alemão afirma que, por mais que não saibamos o que seria o bem absoluto, "sabemos muito bem" o que é o inumano, e que a tarefa da filosofia moral hoje consiste exatamente "na denúncia concreta do inumano".
} 
ela faça reformas legislativas e promova mudanças culturais nesse sentido. Ao fazer isso, a crítica "critica o que é com base no que também é e, portanto, não aponta realmente para além da totalidade existente" (Postone, 2014, p. 111). A essa estratégia Postone (2014, p. 111) opõe a de uma crítica imanente negativa que "não é desenvolvida com base no que é, mas no que poderia ser, como um potencial imanente da sociedade existente", como no caso da crítica de Adorno ao fato que a sociedade não se serve de suas capacidades tecnológicas para eliminar o sofrimento socialmente evitáve ${ }^{17}$. Não se trata, em suma, de criticar a hipocrisia da sociedade, ou sua incapacidade de estar à altura de seus ideais, mas de apontar para as potencialidades inexploradas presentes nela.

A incapacidade de servir-se dos instrumentos disponibilizados pelo avanço tecnológico dos meios de produção para ajudar os indivíduos a se libertarem das necessidades materiais mais básicas é só um exemplo de como a sociedade não realiza suas potencialidades. Também nesse caso, não se trata de apontar para uma discrepância entre realidade e ideal, mas de chamar atenção para a impossibilidade concreta de que a sociedade use seu potencial tecnológico para realizar aquilo que, segundo Adorno (1983, p. 234), é como vimos anteriormente - seu fim, a saber, "a conservação e satisfação da humanidade". Essa impossibilidade concreta é devida ao fato de que a ordem social se fundamenta na lógica da troca e do lucro particular. Para que a sociedade capitalista contemporânea realizasse seu fim último, seria necessário que ela modificasse radicalmente seu fundamento, que ela deixasse de ser o que é, para transformar-se

\footnotetext{
17 Como observa Fleck, esse procedimento é muito usado por Marx, que faz uma crítica que antecipa a de Adorno: "Nos Grundrisse, por exemplo, Marx afirma que a tecnologia poderia libertar os homens do trabalho, mas que as formas de relação social existentes fazem com que os homens trabalhem ainda mais do que trabalhavam com tecnologias menos avançadas" (Fleck, 2015, p. 150).
} 
em algo diferente. Uma transformação radical desse tipo só pode ser imaginada por uma teoria que não se limite à mera descrição de fenômenos sociais e que não tenha receio de pensar a sociedade como "totalidade", na qual tais fenômenos se inserem sem, contudo, representar sua essência. Nas palavras de Habermas (1983, p. 267), Adorno "concebe a sociedade como totalidade, integrada no espírito dialético", pelo qual "o todo não é igual à soma de suas partes". Esse espírito dialético permite constatar que há uma contradição inerente à própria sociedade entre a ordem social que acabou cristalizando-se ao longo da história, por um lado, e as exigências e os anseios de seus membros, por outro. A tarefa do teórico crítico consiste, então, em diagnosticar as formas plurais de sofrimento evitável provocadas pelos arranjos econômicos e sociais dominantes, em mostrar como o caminho tomado pela sociedade contemporânea não era o único possível, e que ainda existem caminhos alternativos para pensarmos e realizarmos uma sociedade mais humana e mais livre.

Essa última afirmação parece remeter à estratégia escolhida por Honneth em $O$ direito da liberdade (2011). Ao reconstruir as transformações históricas experimentadas pelo conceito de liberdade na modernidade, Honneth introduz a noção de Fehlentwicklung, ou desenvolvimento falho, para indicar o fato de que o caminho rumo a uma maior emancipação individual no âmbito das relações individuais, econômicas ou políticas foi interrompido, tomando outra direção, que acabou resultando em formas de dominação sistêmica e de alienação individual. Contudo, essa estratégia argumentativa pressupõe a aceitação de uma filosofia da história centrada na noção de progresso moral, como a adotada por Honneth. Segundo essa visão, as causas dos desenvolvimentos falhos devem ser identificadas em fenômenos contingentes e não estão enraizadas na própria modernidade (isto é, na própria instituição do Estado Moderno, 
no sistema econômico capitalista ou na família burguesa), como ainda pensavam os teóricos da primeira geração. Por isso, Honneth acredita na possibilidade de reformar as instituições características da sociedade moderna, sem que seja necessário aboli-las ou revolucioná-las ${ }^{18}$.

Contra essa visão, defendemos a ideia de que as causas das patologias sociais objetos da crítica social são intrinsecamente ligadas às instituições e às práticas sociais que caracterizam a sociedade moderna e contemporânea, e que os déficits diagnosticados por Honneth não são simples desvios de um caminho que estava levando para a emancipação, mas o resultado lógico do desenvolvimento do potencial opressor intrínseco do Estado, da economia capitalista e da família burguesa. Os progressos identificados por Honneth representam antes um desvio temporário desse desenvolvimento. A "democratização" das relações familiares e de gênero revelou-se parcial e, sobretudo, funcional à inserção das mulheres na força trabalho e à submissão da esfera familiar à lógica do capital, quer em termos de organização da vida familiar com base nas exigências do mundo do trabalho, quer em termos da criação de um mercado de bens e serviços ligados às necessidades de pais que não têm tempo para seus filhos ou de parceiros com diferentes jornadas de trabalho (cf. Hochschild, 1983; 2012). Os avanços em termos de direitos sociais e trabalhistas das décadas de 1960 e 1970 estão sendo anulados paulatinamente em consequência da queda do muro de Berlim, com o qual cessou de existir um sistema socioeconômico alternativo (por mais disfuncional que fosse na realidade), fazendo que os capitalistas já não precisassem garantir a lealdade dos trabalhadores por

\footnotetext{
18 Em seu último livro, A ideia do Socialismo (2015), Honneth parece radicalizar suas críticas, mas, de fato, depois de ter rechaçado as alternativas socialistas tradicionais (começando pelo marxismo), defende um experimentalismo democrático inspirado em Dewey, que não visa abolir as instituições do Estado e do mercado capitalista, mas transformá-las aos poucos por meio de reformas políticas.
} 
meio de concessões materiais. Finalmente, o movimento de ampla participação dos cidadãos nos processos decisórios democráticos coincidiu também com a existência do risco (mais ou menos concreto, mas percebido como tal pelas classes dirigentes e pela maioria das pessoas) de que uma parcela importante da população pudesse escolher modelos políticos alternativos à democracia liberal. Com o fim desse perigo, porém, o próprio processo democrático tem se esvaziado cada vez mais, levando à atual crise da democracia representativa e dos partidos - crise que não se limita aos países europeus, mas alcança dimensão global. As esferas das relações afetivas, do mercado de trabalho e da democracia, analisadas por Honneth, estão submetidas à lógica capitalista de forma inevitável, não de maneira contingente, como pensa o autor alemão. Desde seu surgimento o capitalismo manifestou a tendência de "colonizá-las" e de impor sua lógica (a lógica da valorização do capital) a todas as esferas de ação humana, inclusive as mais espirituais, como a arte ou a educação. Portanto, a crítica social deve recuperar aquela atitude de crítica ao capitalismo que caracterizava a primeira geração da Escola de Frankfurt e que foi deixada de lado pelos representantes das gerações seguintes, de Habermas a Honneth. Isso explica, talvez, o interesse renovado por Adorno ou até por Marx demonstrado pelos membros da geração atual dessa Escola (cf. Jaeggi; Loick, 2013a; 2013b). Contudo, os teóricos críticos contemporâneos parecem mais preocupados em fazer metateoria - isto é, em discutir quais deveriam ser tarefa, objeto e metodologia da Teoria Crítica - do que em realizar concretamente um diagnóstico do presente (cf. Celikates, 2009; Jaeggi, 2013; Stahl, 2013), com a parcial exceção de alguns autores que chamam atenção para a necessidade de a Teoria Crítica tornar a ocupar-se de economia política (cf. Azmanova, 2014). Esse apelo parece ser tanto mais atual à luz do crescente mal-estar em relação ao capitalismo em sua forma neoliberal - mal-estar que está 
tomando parcelas sempre maiores da população também nos países economicamente mais desenvolvidos.

Cabe a uma Teoria Crítica, que queira estar à altura dos tempos, elaborar um diagnóstico social que seja capaz de recuperar a dimensão econômica esquecida por tantas décadas em prol de uma versão "prescritiva” da teoria (particularmente no caso de Habermas). Isso não significa a volta ao marxismo ortodoxo, nem a formas de determinismo econômico ou de materialismo histórico ou dialético, muito pelo contrário: significa simplesmente recuperar a inevitável e necessária dimensão econômica e material sem a qual a liberdade humana permanece vazia e irrealizada. Nesse sentido, o materialismo de Adorno, que vem à tona na insistência sobre a satisfação das carências básicas, sobre o potencial tecnológico dos meios de produção e sobre os interesses das classes dominantes não resulta na negação de uma dimensão mais "espiritual” ou ideal, ligada à afirmação da liberdade individual. Como afirmei anteriormente, a verdadeira negação materialista de tal liberdade se encontra antes na forma de liberalismo atualmente dominante, a saber, no neoliberalismo, bem como no apelo para as presumidamente imutáveis leis da economia e do mercado feito hoje por teóricos sociais e economistas imbuídos do mesmo espírito que animava os positivistas dos tempos de Horkheimer ou de Berlin, Mills e Adorno. Tanto hoje como naqueles tempos, os defensores do status quo se escondem atrás da presumida neutralidade política e axiológica de suas teorias e da presumida superioridade do método científico meramente descritivo. Por isso, uma teoria política que queira estar à altura do seu tempo deve hoje confrontar-se, em primeiro lugar, com essas posições e desmascarar a sua parcialidade e natureza ideológica, como o fizeram os autores mencionados neste artigo. Fazer teoria política significa sempre tomar uma posição política específica. Quem afirme 
não querer fazer isso, ou mente, ou não está fazendo teoria política.

\section{Alessandro Pinzani}

é professor de ética e Filosofia política na Universidade Federal de Santa Catarina (UFSC) e livre docente em Filosofia pela Universidade de Tübingen.

\section{Bibliografia}

ADORNO, T. W. 1983 [1974]. Introdução à controvérsia sobre o

positivismo na sociologia alemã. In: CIVITA, V. (ed.). Benjamin,

Habermas, Horkheimer, Adorno: os pensadores: textos escolhidos. São Paulo:

Abril, pp. 215-263. (Coleção Os pensadores, v. 6). 1996 [1963]. Probleme der Moralphilosophie. Frankfurt am Main:

Suhrkamp. . 2008 [1964]. Philosophische Elemente einer Theorie der Gesellschaft.

Frankfurt am Main: Suhrkamp. 2009. Dialética negativa. Rio de Janeiro: Jorge Zahar.

2014. A disputa do positivismo na sociologia alemã. São Paulo: Ícone.

ANKERSMIT, F. R. 1996. Aesthetic politics: political philosophy beyond fact and value. Stanford: Stanford University Press.

ARENDT, H. 2007 [1958]. A condição humana. 10. ed. Rio de Janeiro: Forense.

AZMANOVA, A. 2014. Crisis? capitalism is doing very well: how is critical theory? Constellations, v. 21, n. 3, pp. 351-365.

BECKER, H. S. 1967. Whose side are we on?. Social Problems, v. 14, n. 3, pp. 239-247.

BERLIN, I. 1999 [1978]. Does political theory still exist?. In:

BERLIN, I. Concepts and categories: philosophical essays. Princeton, NJ:

Princeton University Press. v. 2, pp. 143-172.

CELIKATES, R. 2009. Kritik als soziale Praxis: Gesellschaftiche

Selbstverständigung und kritische Theorie. Frankfurt am Main; New York:

Campus.

COBBAN, A. 1953. The decline of political theory. Political Science

Quarterly, v. 68, n. 3, pp. 321-337.

COMTE, A. 1983 [1842]. Curso de filosofia positiva e outros escritos.

São Paulo: Abril. Coleção Os Pensadores, v. 10).

DURKHEIM, É. 1982 [1897]. O suicídio e outros escritos. São Paulo: Abril.

(Coleção Os pensadores, v. 15). 
EASTON, D. 1951. The decline of modern political theory. The Journal of Politics, v. 13, n. 1, pp. 36-58.

FLECK, A. O. 2015. Theodor W. Adorno: um crítico na era dourada do capitalismo. Tese de doutorado em Filosofia. Florianópolis: UFSC.

FOUCAULT, M. 1979. Microfísica do poder. Rio de Janeiro: Graal.

GEUSS, R. 2010 [2009]. Politics and the imagination. Princeton, NJ: Princeton University Press.

HABERMAS, J. 1983a. Teoria analítica da ciência e dialética. In: CIVITA, V. (ed.). Benjamin, Habermas, Horkheimer, Adorno: textos escolhidos. São Paulo: Abril, pp. 267-289. (Coleção Os pensadores, v. 6). . 1983b. Conhecimento e interesse. In: CIVITA, V. (ed.). Benjamin, Habermas, Horkheimer, Adorno: textos escolhidos. São Paulo: Abril, pp. 291-302. (Coleção Os pensadores, v. 6).

HEGEL, G. W. F. 2010 [1820]. Linhas fundamentais da filosofia do direito. Tradução de Paulo Meneses et al. São Leopoldo; São Paulo: Unisinos; Loyola.

HOCHSCHILD, A. R. 1983. The managed heart: commercialization of human feelings. Berkeley: University of California Press.

2012. The outsourced self: what happens when we pay others to live our lives for us. New York: Picador.

HONNETH, A. 2011. Das Recht der Freiheit: Grundriß einer demokratischen Sittlichkeit. Berlin: Suhrkamp. 2015. Die Idee des Sozialismus: Versuch einer Aktualisierung. Berlin: Suhrkamp.

HORKHEIMER, M. 1983. Teoria tradicional e teoria crítica. In: CIVITA, V. (ed.). Benjamin, Habermas, Horkheimer, Adorno: textos escolhidos. São Paulo: Abril, pp. 125-162. (Coleção Os pensadores, v. 6).

JAEGGI, R. 2013. O que há (se de fato há algo) de errado com o capitalismo? três vias de crítica do capitalismo. Cadernos de Filosofia Alemã: Crítica e Modernidade, v. 20, n. 2, pp. 13-36.

JAEGGI, R.; LOICK, D. (eds.). 2013a. Nach Marx: Philosophie, Kritik, Praxis. Berlin: Suhrkamp. . (eds.). 2013b. Karl Marx: Perspektiven der Gesellschaftskritik. Berlin: Akademie.

KANT, I. 2002 [1795]. À paz perpétua e outros opúsculos. Tradução de Artur Morão. Lisboa: Edições 70. 2013 [1797]. Metafísica dos costumes. Tradução de Monique Hulshof et al. Petrópolis: Vozes.

LACLAU, E.; MOUFFE, C. 2001 [1985]. Hegemony and socialist strategy: towards a radical democratic politics. 2. ed. London: Verso. 
LASLETT, P. 1956. Introduction. In: LASLETT, P. (ed.). Philosophy, politics and society: a collection. Oxford: Blackwell, pp. vii-xv.

LUKES, S. 2005 [1974]. Power: a radical view. 2. ed.. New York: Palgrave. MACHIAVEL, N. 2007 [1513]. O príncipe. Tradução de José Antônio Martins. São Paulo: Hedra.

MILLS, C. W. 2000 [1959]. The sociological imagination. Oxford: Oxford University Press.

PINZANI, A. 2012. Teoria crítica e justiça social. Civitas, v. 12, n. 1, pp. 88-106.

PLATÃO. 1999. As leis. São Paulo: Edipro. 2008. A república. 11. ed. Lisboa: Fundação Calouste Gulbenkian. POSTONE, M. 2014. Tempo, trabalho e dominação social: uma reinterpretação da teoria crítica de Marx. São Paulo: Boitempo.

RAWLS, J. 2002 [1971]. Uma teoria da justiça. Tradução de Almiro Pisetta e Lenita M. Rìmoli Esteves. São Paulo: Martins Fontes. 2011 [1993]. O liberalismo politico. Tradução de Álvaro de Vita e Luís Carlos Borges. São Paulo: Martins Fontes.

ROMERO, J. M. (ed.). 2014: Immanente Kritik heute: Grundlagen und Aktualität eines sozialphilosophischen Begriffs. Bielefeld: Transcript.

STAHL, T. 2013. Immanente Kritik: Elemente einer Theorie sozialer Praktiken. Frankfurt am Main; New York: Campus.

TAYLOR, C. 1985. Human agency and language. Cambridge, MA:

Cambridge University Press. (Coleção Philosophical Papers, v. 1).

VINCENT, A. 2004. The nature of political theory. Oxford: Oxford University Press.

WALZER, M. 1981. Philosophy and democracy. Political Theory, v. 9, n. 3, pp. 379-399.

WEBER, M. 1988 [1921]. Die protestantische Ethik und der Geist des Kapitalismus. In: WEBER, M. Gesammelte Aufsätze zur Religionssoziologie. 9. ed. Tübingen: Mohr Siebeck. v. 1, pp. 17-206.

WINCH, P. 1958. The idea of a social science and its relation to philosophy.

London: Routledge. 


\section{)}

\section{TEORIAS POLÍTICAS TRADICIONAIS E TEORIA CRÍTICA}

\section{ALESSANDRO PINZANI}

Resumo: Este artigo defende, primeiramente, a ideia de que toda e qualquer teoria política é intrínseca e inevitavelmente normativa, mesmo quando afirma ser meramente descritiva e empírica. Ao fazer isso, o artigo estabelece uma diferença central entre teorias normativas "externalistas" e teorias normativas que assumem uma posição de crítica imanente. Em seguida defende uma posição próxima da defendida por Horkheimer, em 1937, e por Adorno, em 1961, de que é necessário desenvolver uma teoria crítica da sociedade que rechace a atitude positivista ou cientificista e reconheça as contradições inerentes ao seu próprio objeto. Para tanto, oferecerá algumas observações sobre possíveis caminhos para uma Teoria Crítica capaz de entender e criticar a sociedade contemporânea.

Palavras-chave: Teoria política; Teoria crítica; Positivismo; Normativismo.

\section{TRADITIONAL POLITICAL THEORIES AND CRITICAL THEORY}

Abstract: This article defends, firstly, that every political theory is intrinsically and unavoidably normative, even when it claims to be merely descriptive and empirical. In doing so, the article establishes a central difference between "externalist" normative theories and normative theories that choose a position of immanent critique. Secondly, it takes a position that is close to the one defended by Horkheimer in 1937 and Adorno in 1961, that of the necessity of developing a critical theory of society that refuses positivism and scientism and acknowledges the contradictions inherent to its own subject. To this end, it shall offer some remarks about possible paths 
Resumos | Abstracts

for a Critical Theory capable of understanding and criticizing contemporary society.

Keywords: Political theory; Critical theory; Positivism; Normativism. Recebido: 30/03/2017Ａprovado: 23/06/2017 